Supplement of Atmos. Chem. Phys., 18, 14681-14693, 2018

https://doi.org/10.5194/acp-18-14681-2018-supplement

(C) Author(s) 2018. This work is distributed under

the Creative Commons Attribution 4.0 License.

(c) (i)

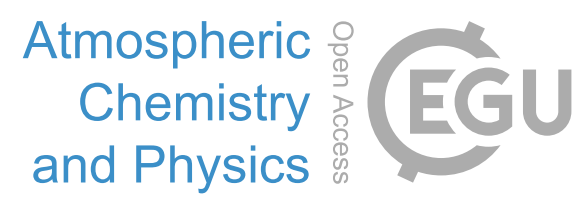

Supplement of

\title{
Cloud scavenging of anthropogenic refractory particles at a mountain site in North China
}

\section{Lei Liu et al.}

Correspondence to: Weijun Li (liweijun@zju.edu.cn)

The copyright of individual parts of the supplement might differ from the CC BY 4.0 License. 


\section{AFM analysis}

Three-dimensional morphology of aerosol particles was acquired by an atomic force microscope (AFM, Dimension Icon, Veeco Instruments Inc., USA) with a tapping mode under ambient conditions. When conducting the AFM analysis, parameters were set as follows: imaging force between 1 and $1.5 \mathrm{nN}$, scanning rate between 0.5 and $0.8 \mathrm{~Hz}$, and scanning range size at $10 \mu \mathrm{m}$ with a resolution of 512 pixels per length. Bearing area (S) and bearing volume (V) of each analyzed particle were obtained by the NanoScope Analysis software (Version 1.50, Bruker Corporation, USA) and then ECD and equivalent spherical diameters (ESD) were calculated according to S and V, respectively. By plotting ESD versus ECD, we found that ESD and ECD had a robust linear relationship (Fig. S1, ESD $=0.4952 \times \mathrm{ECD}, r^{2}=0.9782$ ). Therefore, the ECD of individual aerosol particles measured from the iTEM software can be further converted to ESD through the linear regression equation.

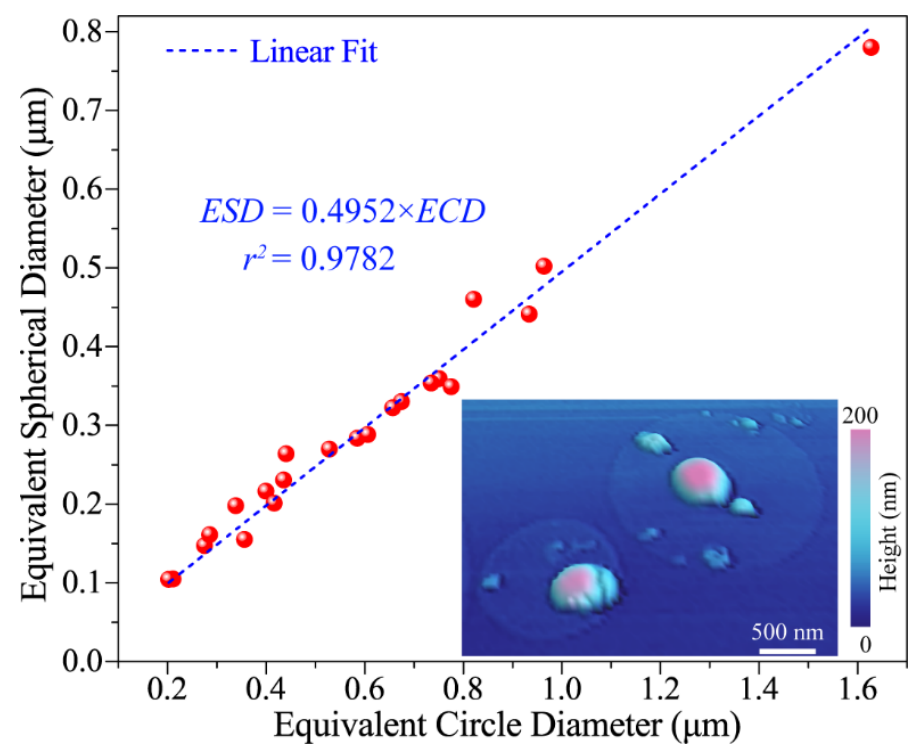

Figure S1. Plot of equivalent spherical diameter (ESD) versus equivalent circle diameter (ECD) of individual dry particles on the substrate analyzed by atomic force microscope (AFM). The AFM image shows the morphology and large rims of two cloud residual particles. 


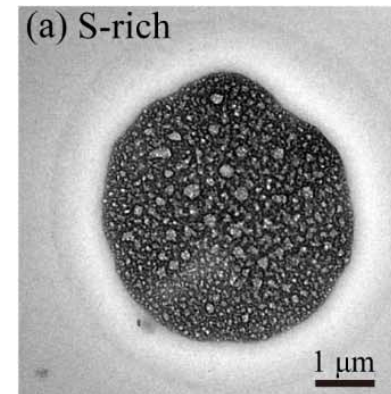

(e) fly ash (b) soot

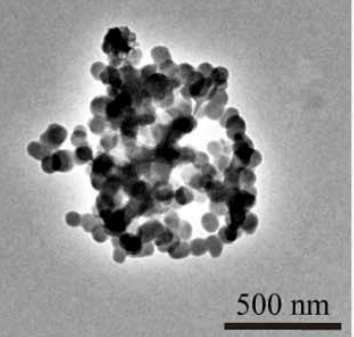

(f) Fe-rich (c) $\mathrm{OM}$

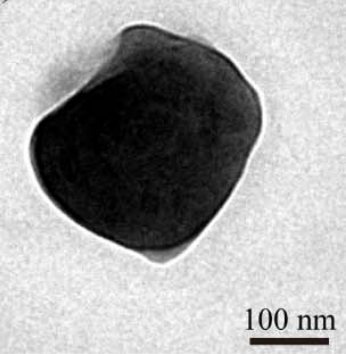

(g) Fe-aggregation

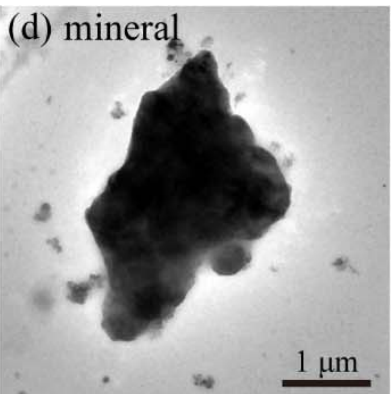

(h) $\mathrm{Zn}-\mathrm{Pb}$

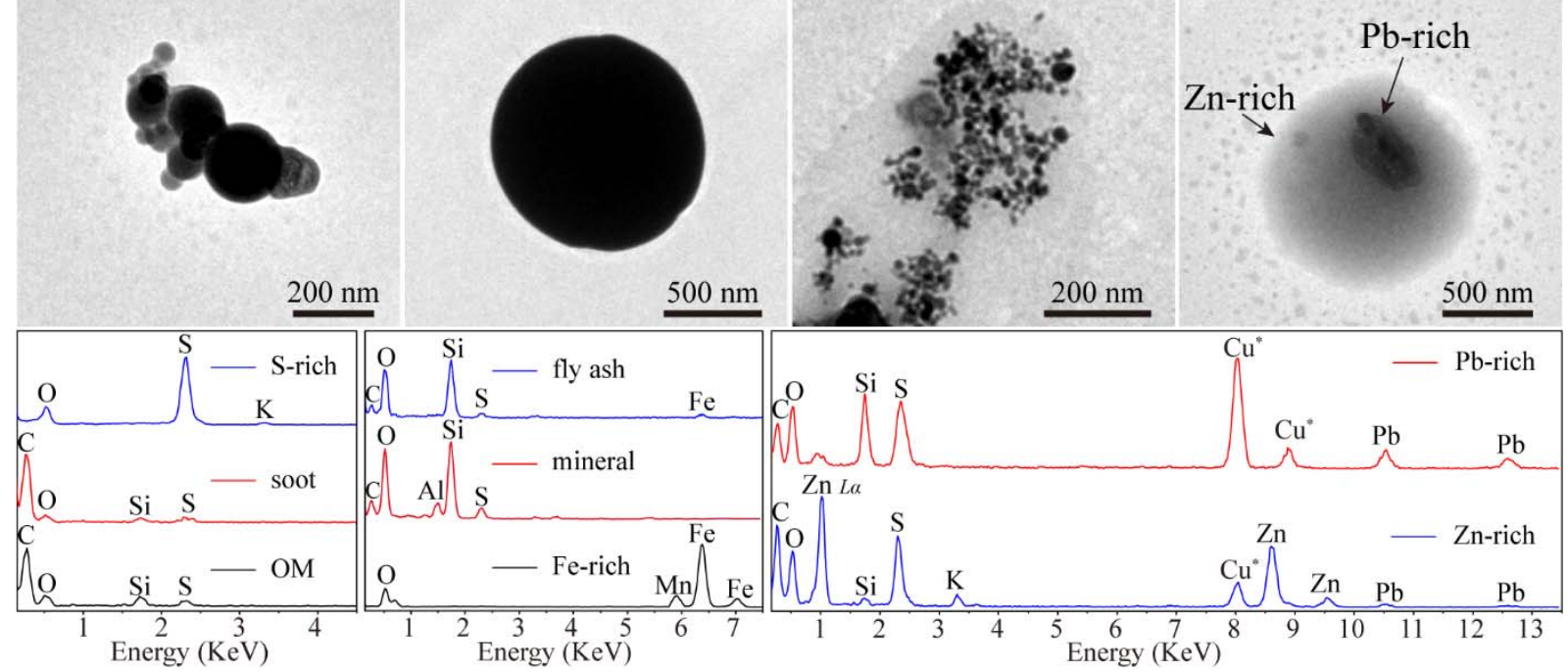

Figure S2. Typical TEM images and EDS spectra of different basic types of individual particles. (a) S-rich, (b) soot, (c) organic matter (OM), (d) mineral, (e) fly ash, and (f-h) metal particles including Fe-rich, Fe-aggregation, and Zn-Pb. 
(a) cloud INT

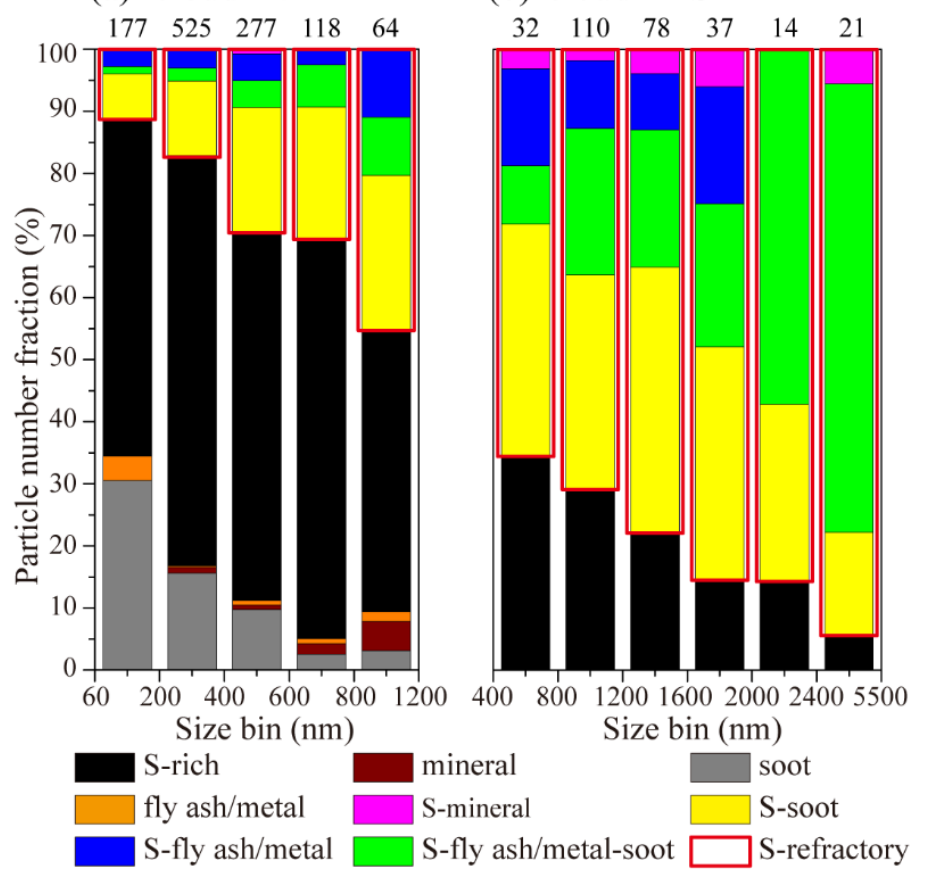

Figure S3. Size-resolved number fractions of different particle types in cloud RES and INT particles. The number of analyzed particles in each size bin is shown above each column. In total, 292 cloud RES and 1161 cloud INT particles were analyzed. 